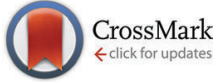

Cite this: Phys. Chem. Chem. Phys., 2016, 18, 26133

Received 7th June 2016 Accepted 25th August 2016

DOI: $10.1039 / \mathrm{c} 6 \mathrm{cp} 03958 \mathrm{~h}$

www.rsc.org/pccp

\section{DFT global optimisation of gas-phase and MgO-supported sub-nanometre AuPd clusters $\dagger$}

\author{
Heider A. Hussein, ${ }^{a b}$ Jack B. A. Davis ${ }^{a}$ and Roy L. Johnston ${ }^{{ }^{a}}$ \\ The Birmingham Parallel Genetic Algorithm (BPGA) has been adopted for the global optimization of \\ free and $\mathrm{MgO}(100)$-supported $\mathrm{Pd}, \mathrm{Au}$ and AuPd nanocluster structures, over the size range $\mathrm{N}=4-10$. \\ Structures were evaluated directly using density functional theory, which has allowed the identification \\ of $\mathrm{Pd}, \mathrm{Au}$ and AuPd global minima. The energetics, structures, and tendency of segregation have been \\ evaluated by different stability criteria such as binding energy, excess energy, second difference in \\ energy, and adsorption energy. The ability of the approach in searching for putative global minimum has \\ been assessed against a systematic homotop search method, which shows a high degree of success.
}

\section{Introduction}

Nanomaterials have at least one dimension on the nanometer scale $(1-100 \mathrm{~nm})$. They have recently emerged as new materials that bridge the gap between atoms or molecules and bulk materials, and they have attracted remarkable interest owing to their numerous potential applications. ${ }^{1}$ Nanomaterials contribute to many new technological applications in various fields, such as medicine, materials, physics, and chemistry. These new applications came as a consequence of their novel chemical and physical properties which are due to electronic and quantum effects and the high surface-area-to-volume ratio. ${ }^{1-3}$

The ability to control the surface and structural properties of nanostructures in the nanometre range and their suitable integration with different scientific research concepts have attracted widespread interest from researchers because of their use in many emerging technological applications. ${ }^{4-7}$ AuPd nanostructures, in particular, have been investigated previously for a number of applications, including catalytic applications. AuPd catalysts have been found to be promising candidates for a wide variety of chemical reactions, such as cyclohexane oxidation, ${ }^{8}$ NO reduction, ${ }^{9}$ CO oxidation, ${ }^{10,11}$ direct synthesis of hydrogen peroxide, ${ }^{12,13}$ and synthesis of aldehydes from primary alcohols. ${ }^{14}$

Theoretically, AuPd systems have been studied to rationalize their catalytic activities. Studies have been conducted on some of the AuPd clusters in the gas phase ${ }^{15}$ and supported on surfaces (e.g. $\mathrm{MgO}(100)$ and $\mathrm{TiO}_{2}(110)$ slabs) ${ }^{16-18}$ in addition

\footnotetext{
${ }^{a}$ School of Chemistry, University of Birmingham, Birmingham, B15 2TT, UK. E-mail: r.l.johnston@bham.ac.uk; Tel: +44 (0)1214 147477

${ }^{b}$ Department of Chemistry, College of Science, University of Kufa, Najaf, Iraq $\dagger$ Electronic supplementary information (ESI) available. See DOI: 10.1039/ c6cp $03958 \mathrm{~h}$
}

to the simulation of the interaction of pure Au and Pd nanoparticles and AuPd nanoparticles with atoms or small molecules such as S, H, NO, and CO. ${ }^{9,10,19,20}$ However to date there have been few studies of small AuPd clusters supported on $\mathrm{MgO}$. Subnanometre clusters are groups or aggregates of a few to tens of metal atoms which are $(<1.0 \mathrm{~nm})$ in size. These smaller clusters are of interest in catalysis due to the potential for enhanced activity and selectivity.

The rarity of theoretical studies concerned with $N=4-10 \mathrm{AuPd}$ nanoalloys, whether in the gas phase or supported on MgO, has led us to select the Au-Pd system to be studied. In order to find the global minima for the pure and mixed AuPd clusters in the gas phase and on $\mathrm{MgO}$, we have used the Birmingham Parallel Genetic Algorithm (BPGA) to enable global optimisation directly at the DFT level. ${ }^{21}$

\section{Methodology}

\subsection{BPGA-DFT}

The BPGA-DFT approach was applied for cluster sizes ranging from $N=4-10$ for all compositions of free and $\mathrm{MgO}(100)$ supported AuPd nanoalloys, as well as the pure Au and Pd clusters. Gamma-point DFT calculations were performed with the Vienna ab initio Simulation Package (VASP) $\operatorname{code}^{22}$ utilising projected-augmented wave (PAW) pseudopotentials and the PBE exchange correlation functional. ${ }^{23,24}$ A plane-wave basis set was used. The energy was truncated at $400 \mathrm{eV}$. MethfesselPaxton smearing, with a sigma value of $0.01 \mathrm{eV}$, was implemented to improve convergence. ${ }^{25}$

The Birmingham Parallel Genetic Algorithm (BPGA) has been adopted for the evaluation of potential cluster structures. This method is the latest open-source genetic algorithm ${ }^{26}$ improving on the Birmingham Cluster Genetic Algorithm 
(BCGA), a genetic algorithm for determining the lowest energy isomers of nanoparticles and nanoalloys up to approximately 100 atoms. $^{27}$

BPGA employs a pool methodology to evaluate structures in parallel. In each run, multiple BPGA instances are implemented, and in each instance, a set of processes are run in parallel and independently. ${ }^{15,28}$ Numerous random geometries are initially generated to form a population. ${ }^{21}$ The generated structures of a given population are then geometrically relaxed (local energy minimized). ${ }^{15}$ Once the local minimization of the initial pool structures is completed, crossover and mutation are conducted on the lowest energy individuals in the population.

Clusters are selected for crossover using tournament selection with crossover being performed using the cut-and-splice method introduced by Deaven and Ho. ${ }^{29}$ The mutation operators are set as a homotop-swap for nanoalloys and a random atom displacement for the pure clusters. The energy of any newly created structure is compared with those of the other structures in the pool. The highest-energy isomer is replaced with the new lower energy isomer.

For the supported clusters, owing to the high computational cost of $\mathrm{MgO}(100)$ slab relaxation, the slab is not relaxed during the local minimization, but the cluster geometries are optimised in the presence of the fixed slab. The supported cluster is optimised within a sphere placed at $1.5 \AA$ over a $6 \times 6 \times 2$ slab of $\mathrm{MgO}(100)$ with a $14.7 \AA$ vacuum spacing (as shown in Fig. 1), to ensure that there are no cluster-cluster or other non-physical interactions arising due to the periodic boundary conditions. The interactions between the cluster and the surface have been replicated using two layers of $\mathrm{MgO}(100) .{ }^{17,30-32}$ The efficacy of replicating a surface behaviour and the cluster properties by using two layers of the $\mathrm{MgO}$ slab has previously been confirmed. ${ }^{33,34}$ Random rotation of the cluster regarding the fixed surface is used as a mutation operator when optimising the supported clusters.

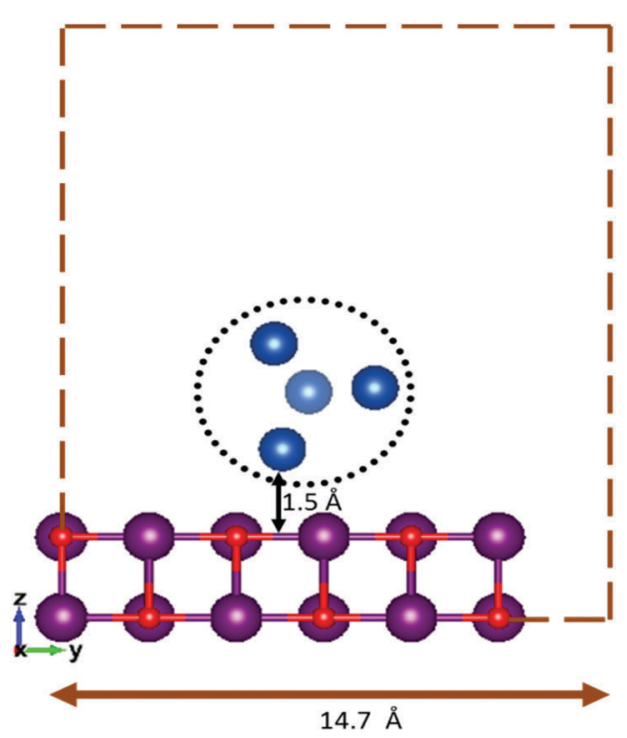

Fig. 1 Fixed height and vacuum spacing for an initial random geometry of the surface-supported cluster.

\subsection{Energy calculations}

The average binding energy per atom $E_{\mathrm{b}}$ is given by

$$
E_{\mathrm{b}}=\frac{1}{N}\left[E_{\left(\mathrm{Au}_{m} \mathrm{Pd}_{n}\right)}-m E_{\mathrm{Au}}-n E_{\mathrm{Pd}}\right]
$$

where $m, n, E_{\mathrm{Au}}$, and $E_{\mathrm{Pd}}$ are the numbers of $\mathrm{Au}$ and $\mathrm{Pd}$ atoms and the electronic energies of a single Au or Pd atom, respectively, and $N$ is the total number of atoms $(N=m+n)$.

The stability of each cluster, relative to its neighbours, is indicated by the second difference in energy $\Delta_{2} E$ which is given by

$$
\Delta_{2} E=E_{\left(\mathrm{A}_{(N+1)}\right)}+E_{\left(\mathrm{A}_{(N-1)}\right)}-2 E_{\left(\mathrm{A}_{N}\right)}
$$

where $\mathrm{A}$ is $\mathrm{Au}$ or $\mathrm{Pd}, E_{\left(\mathrm{A}_{N}\right)}$ corresponds to the total energy of the N-atom cluster and $E_{\left(\mathrm{A}_{(N+1)}\right)}$ and $E_{\left(\mathrm{A}_{(N-1)}\right)}$ are the neighbouring clusters, with one atom more and one atom less, respectively.

Evaluation of the effect of mixing in binary nanoalloys has been achieved by calculating the excess energy $\Delta$ which is given by

$$
\Delta=N E_{\left(\mathrm{Au}_{m} \mathrm{Pd}_{n}\right)}-m E_{\left(\mathrm{Au}_{N}\right)}-n E_{\left(\mathrm{Pd}_{N}\right)}
$$

where $E_{\left(\mathrm{Au}_{m} \mathrm{Pd}_{n}\right)}$ is the total energy of the nanoalloy and $E_{\left(\mathrm{Au}_{N}\right)}$ and $E_{\left(\mathrm{Pd}_{N}\right)}$ are the energies of the pure Au and Pd clusters with the same total number of atoms as $\mathrm{Au}_{m} \mathrm{Pd}_{n}$.

The adsorption energy, $E_{\text {ads }}$, of the $\mathrm{Au}_{m} \mathrm{Pd}_{n}$ cluster on the $\mathrm{MgO}(100)$ support was calculated by

$$
E_{\mathrm{ads}}=E_{\left(\mathrm{slab}_{\mathrm{Au}} \mathrm{Pd}_{n}\right)}-E_{(\mathrm{slab})}-E_{\left(\mathrm{Au}_{m} \mathrm{Pd}_{n}\right)}
$$

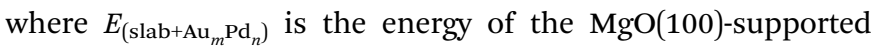
cluster, $E_{\text {(slab) }}$ is the energy of the $\mathrm{MgO}(100)$ surface, and $E_{\left(\mathrm{Au}_{m} \mathrm{Pd}_{n}\right)}$ is the energy of the free $\mathrm{Au}_{m} \mathrm{Pd}_{n}$ cluster, locally minimized in the gas phase.

\section{Results and discussion}

\subsection{Global optimisation of free and supported $\mathrm{Au}, \mathrm{Pd}$, and AuPd clusters}

3.1.1 Gold clusters. The putative global minima for pure Au clusters, $4 \leq N \leq 10$, are shown in Fig. 2 and their energies, structures, and point groups are listed in Table S1 (see the ESI $\dagger$ ). Putative global minima for the $\mathrm{MgO}(100)$-supported Au clusters, $4 \leq N \leq 10$, are shown in Fig. 3 and 4 .

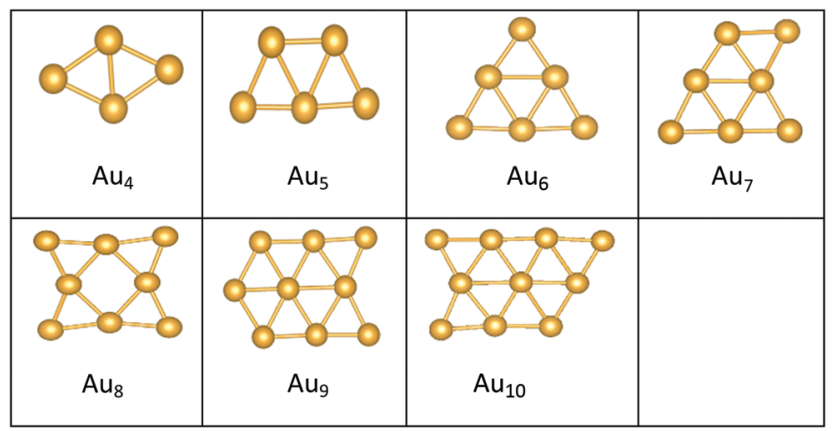

Fig. 2 Putative global minimum structures of free $A u_{N}$ clusters, $N=4-10$. 


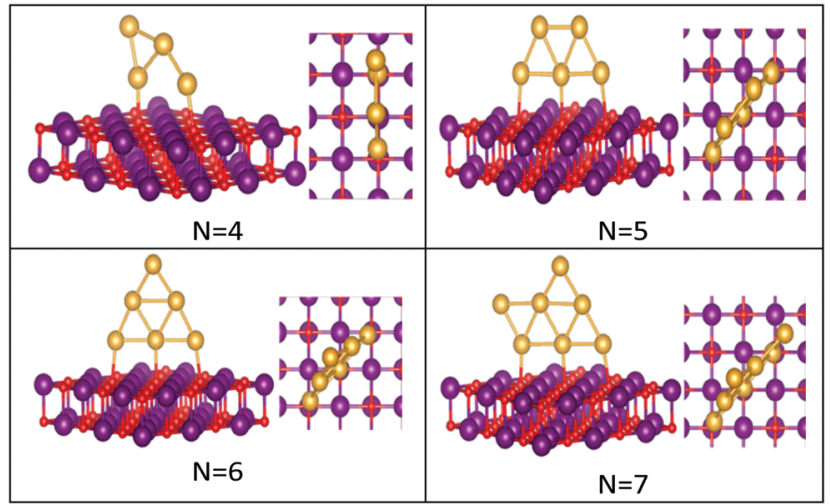

Fig. 3 Putative global minimum structures of $\mathrm{MgO}(100)$-supported $\mathrm{Au}_{N}$ clusters, $N=4-7$. $\mathrm{Au}, \mathrm{Mg}$ and $\mathrm{O}$ are shown in gold, purple, and red, respectively.

The best structures obtained for all studied free Au clusters in this size range show planar configurations, as previously reported. ${ }^{35-37}$ Our results satisfactorily concur with those presented by previous theoretical studies on Au clusters up to 10 atoms $^{38-40}$ and by experimental research on Au cation clusters up to 7 atoms. ${ }^{41}$ In addition, our results agree with the findings of Zhao and co-workers ${ }^{42}$ concerning the planar structures of small Au clusters up to 6 atoms. However, some differences are observed for $\mathrm{Au}_{7}, \mathrm{Au}_{8}$, and $\mathrm{Au}_{9}$, which are predicted to be $3 \mathrm{D}$ by $\mathrm{Zhao}{ }^{42}$

Global minima for the supported Au clusters are all found to be still planar, with some slight deviation from the planarity for $\mathrm{Au}_{9}$ and $\mathrm{Au}_{10}$. They are found to lie roughly perpendicular to the $\mathrm{MgO}$ surface, due to the "metal-on-top" effect. ${ }^{32}$ Bonding of two atoms of $\mathrm{Au}$ to $\mathrm{O}$ atoms has led to an increase in the $\mathrm{Au}-\mathrm{Au}$ distance from (2.68) to (3.76) $\AA$, forming an elongated $\mathrm{Au}_{4}$ cluster on the surface. ${ }^{43} N=(5-8)$ Au clusters on the surface have similar structures to that in the gas phase, whereas $\mathrm{Au}_{9}$ adopts a different pseudo-planar configuration and $\mathrm{Au}_{10}$ keeps the gas phase structure but with a bend in one of its edges.

The preference for Au clusters with planar structures may be attributed to the non-additive many-body interactions in

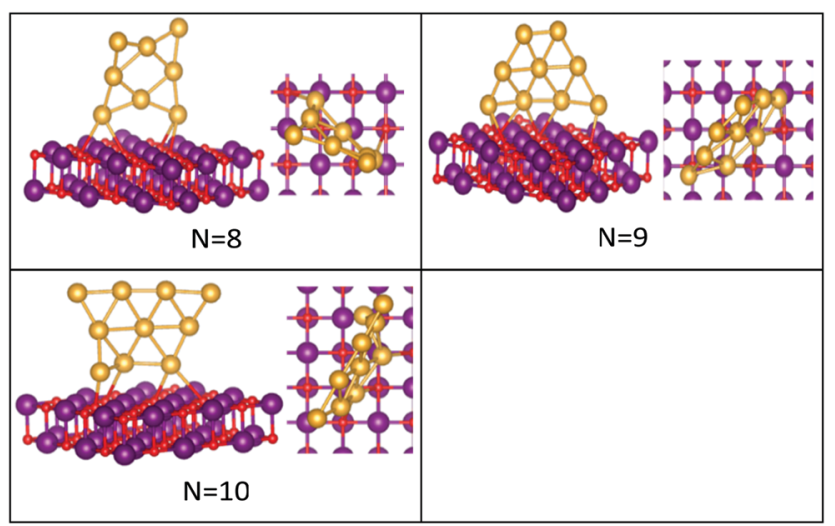

Fig. 4 Putative global minimum structures of $\mathrm{MgO}(100)$-supported $\mathrm{Au}_{N}$ clusters, $N=8-10$. $\mathrm{Au}, \mathrm{Mg}$ and $\mathrm{O}$ are shown in gold, purple, and red, respectively.

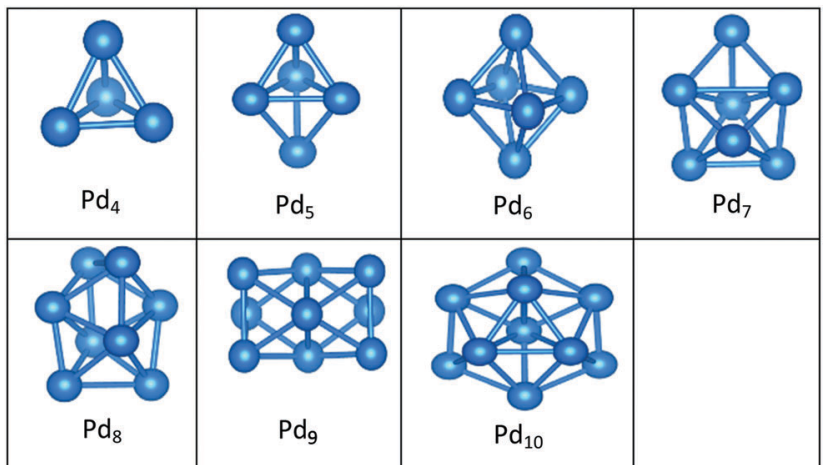

Fig. 5 Putative global minimum structures of free $P d_{N}$ clusters, $N=4-10$.

comparison with the additive two-body forces in $\mathrm{Au}$ atoms, ${ }^{44}$ and the involvement of the d electrons of $\mathrm{Au}$ in bonding in planar structures is higher than in $3 \mathrm{D}$ ones. ${ }^{39}$ Some researchers have considered "relativistic effects" 45 in interpreting the preference for planar structures, attributing such a preference to the decrease in the $5 \mathrm{~d}-6 \mathrm{~s}$ orbital spacing that strengthens s-d hybridization. ${ }^{46}$

3.1.2 Palladium clusters. Fig. 5 and 6 show the putative global minima for free and supported pure Pd clusters, and Table S1 lists the energies, structures, and point groups for free clusters (see the ESI $\dagger$ ).

In contrast to $\mathrm{Au}$ clusters, Pd clusters do not adopt 2D structures; instead, they all have 3D motifs that mostly favour

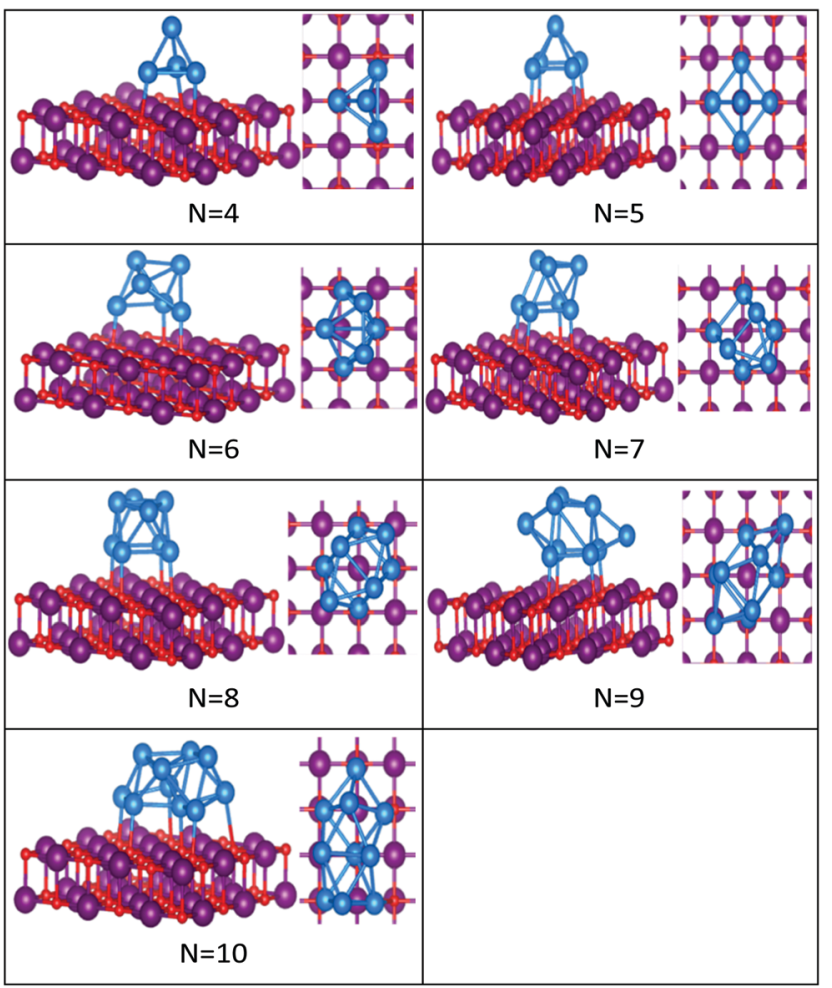

Fig. 6 Putative global minimum structures of $\mathrm{MgO}(100)$-supported $\mathrm{Pd}_{N}$ clusters, $N=4-10$. Pd, $M g$ and $O$ are shown in blue, purple, and red, respectively. 
deltahedral (triangular faced) compact structures as lowest-energy configurations. Global minima for the gas phase Pd clusters are all found to be different from their supported structures with the exception of $\mathrm{Pd}_{4}$ which remains a tetrahedron.

Landman et $a l^{47}$ investigated the structural properties of neutral $\mathrm{Pd}_{N}$ isomers with $N=1-7$ using DFT. These researchers clarified that the global minima are 3D for clusters with more than 3 atoms, which is in full agreement with the gas-phase Pd clusters for sizes $4 \leq N \leq 7$ reported here. Thus, the global minimum of free $\mathrm{Pd}_{5}$ is the trigonal bipyramid. On the surface this structure distorts to give a square-based pyramidal structure. The four Pd atoms of the square base are bonded to four different $\mathrm{O}$ atoms of the slab. The octahedral structure of free $\mathrm{Pd}_{6}$ alters to form a bicapped tetrahedron on the surface, forming three $\mathrm{Pd}-\mathrm{O}$ bonds.

We have previously presented BCGA-DFT studies of free $\mathrm{Pd}_{8}$, $\mathrm{Pd}_{9}$, and $\mathrm{Pd}_{10}$ clusters, ${ }^{16,48}$ whose putative global minima were identified as a dodecahedron, an icosahedral fragment, and an incomplete centered icosahedron, respectively. These observations conform to our findings for free clusters. Our supported structures of $\mathrm{Pd}_{7}, \mathrm{Pd}_{8}$, and $\mathrm{Pd}_{9}$ are a capped trigonal prism, a distorted square antiprism, and a distorted tricapped octahedron, respectively. The structure of $\mathrm{Pd}_{10}$ is an icosahedral fragment in the gas-phase. On the surface this global minimum distorts to give a more complex fused structure.

3.1.3 Gold-palladium clusters. The putative global minima for all compositions of free and supported $\mathrm{Au}_{m} \mathrm{Pd}_{n}$ clusters, $4 \leq(m+n) \leq 10$, are shown in Fig. 7-16 and the energies, structures, and point groups of all free clusters are given in Table S2 (see the ESI $\dagger$ ). On going from monometallic clusters to nanoalloys, there is an increase in difficulty of identifying the global minimum (GM) structure due to the presence of "homotops" in addition to the size effect. ${ }^{49}$

All the favoured structures of $\mathrm{Au}_{1} \mathrm{Pd}_{n} n=3-9$ compositions are 3D. For $N=4-7$ and $N=9$, doping one Au atom into the pure Pd clusters yields geometries which are similar to the pure Pd clusters, as previously reported. ${ }^{35,50} \mathrm{Au}_{1} \mathrm{Pd}_{n} n=7$ and 9 are a bicapped octahedron and a capped face-sharing octahedron, respectively. The $\mathrm{Au}$ atom occupies a low-connectivity vertex or an edge position, as previously reported for larger clusters. ${ }^{51} \mathrm{On}$ the surface, $\mathrm{Au}_{1} \mathrm{Pd}_{n}$ structures are all found to be different from their gas-phase counterparts, with the exception of $\mathrm{Au}_{1} \mathrm{Pd}_{3}$, which remains a tetrahedron.

The 2D structures of Au clusters, discussed in Section (3.1.1), remain the global minima when they are doped with a single Pd atom. The Pd atoms are located in or close to the centre of the clusters. $\mathrm{Au}_{m} \mathrm{Pd}_{1} m=3-5$ clusters have the same structures as the corresponding pure Au clusters, as previously reported. ${ }^{35,50} \mathrm{Au}_{m} \mathrm{Pd}_{1} m=6$ adopts a Pd-centred planar hexagon which is also the core of the clusters with 7 and $8 \mathrm{Au}$ atoms. The cluster for $m=9$ also has a planar global minimum. 2D-3D structural transitions take place at sizes $N=7-10$ on the surface.

It is clear that Pd-rich nanoalloys tend to adopt 3D geometries while 2D-3D structural transitions occur for gold clusters when adding more than one Pd atom. It is worthwhile

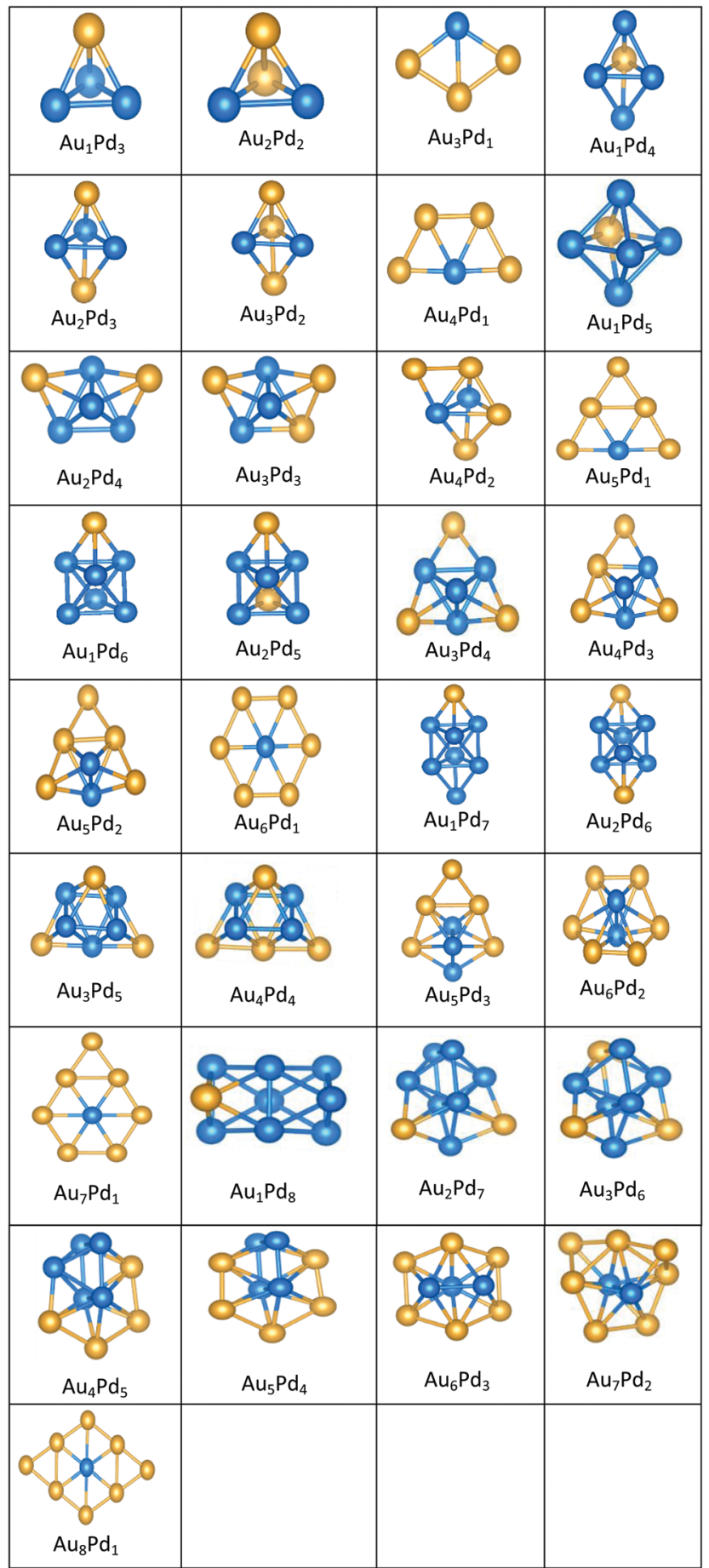

Fig. 7 Putative global minimum structures for all compositions of free AuPd nanoalloys with sizes $N=4-9$, Au and Pd are shown in gold and blue, respectively.

mentioning that most of the lowest energy structures of free $\mathrm{Au}_{m} \mathrm{Pd}_{n}$ clusters for $(n+m)=4-10$, which were calculated recently by Zanti and Peeters ${ }^{35}$ and Palagin and Doye, ${ }^{50}$ are in good agreement with our observations.

The supported and gas-phase structures of $\mathrm{Au}_{1} \mathrm{Pd}_{3}$ and $\mathrm{Au}_{2} \mathrm{Pd}_{2}$ are both tetrahedra. For $\mathrm{Au}_{3} \mathrm{Pd}_{1}$, the supported structure is similar to that of the free cluster, both having a planar 


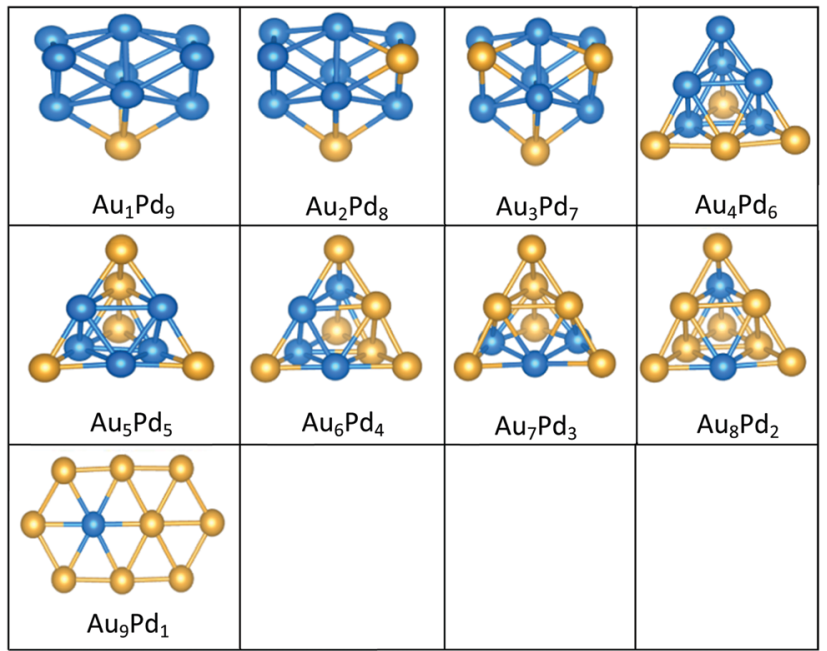

Fig. 8 Putative global minimum structures for all compositions of free AuPd nanoalloys with size $N=10, \mathrm{Au}$ and Pd are shown in gold and blue, respectively.

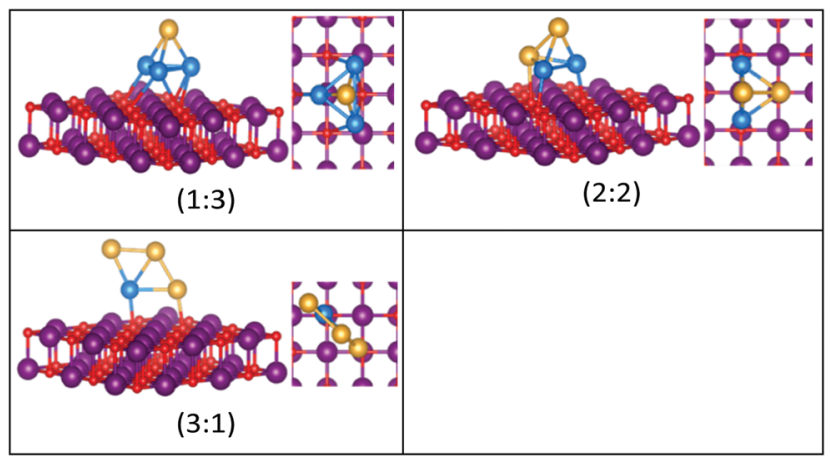

Fig. 9 Putative global minimum structures for compositions of $\mathrm{MgO}(100)$ supported AuPd nanoalloys with size $N=4$. Au, Pd, Mg and $\mathrm{O}$ are shown in gold, blue, purple, and red, respectively.

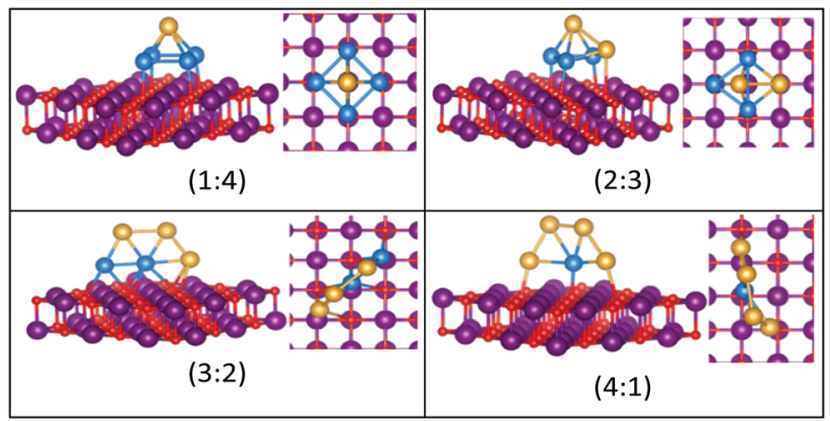

Fig. 10 Putative global minimum structures for compositions of $\mathrm{MgO}(100)$ supported AuPd nanoalloys with size $N=5$. Au, $\mathrm{Pd}, \mathrm{Mg}$ and $\mathrm{O}$ are shown in gold, blue, purple, and red, respectively.

rhombic structure. For all compositions of size $N=4$, the lowest energy conformation for the supported cluster maximises the number of the stronger $\mathrm{Pd}-\mathrm{O}$ interactions.

The gas-phase global minima for $\mathrm{Au}_{1} \mathrm{Pd}_{4}, \mathrm{Au}_{2} \mathrm{Pd}_{3}$ and $\mathrm{Au}_{3} \mathrm{Pd}_{2}$ are all trigonal bipyramid structures, whereas $\mathrm{Au}_{4} \mathrm{Pd}_{1}$

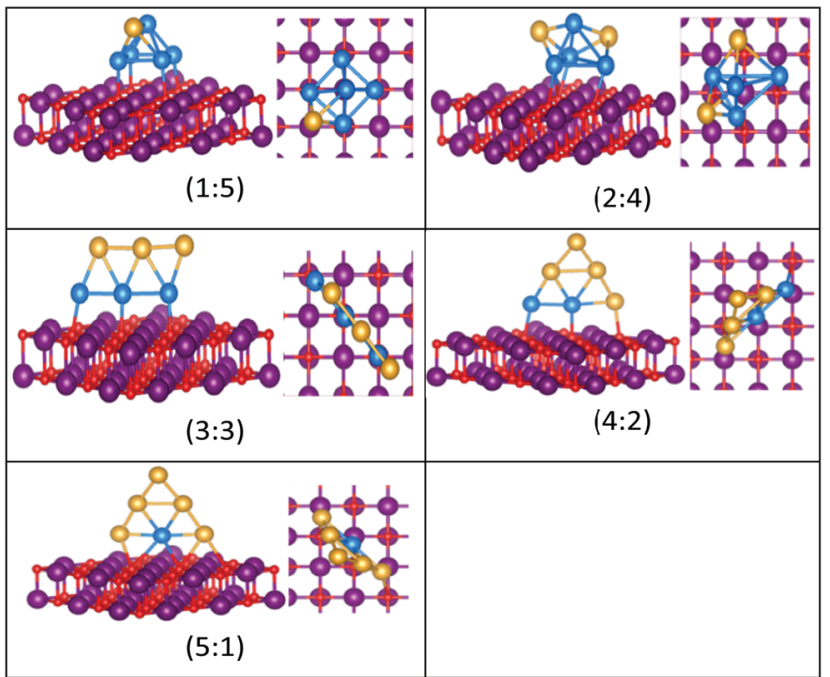

Fig. 11 Putative global minimum structures for compositions of $\mathrm{MgO}(100)$ supported AuPd nanoalloys with size $N=6$. $\mathrm{Au}, \mathrm{Pd}, \mathrm{Mg}$ and $\mathrm{O}$ are shown in gold, blue, purple, and red, respectively.

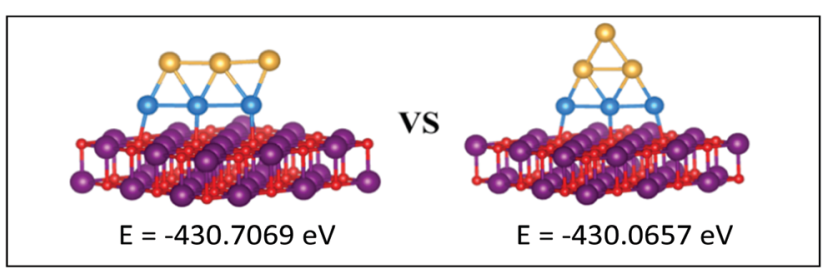

Fig. 12 Putative global minimum (left) versus local minimum (right) for the $\mathrm{MgO}(100)$-supported $\mathrm{Au}_{3} \mathrm{Pd}_{3}$ cluster. $\mathrm{Pd}, \mathrm{Au}, \mathrm{Mg}$ and $\mathrm{O}$ are shown in blue, gold, purple, and red, respectively.

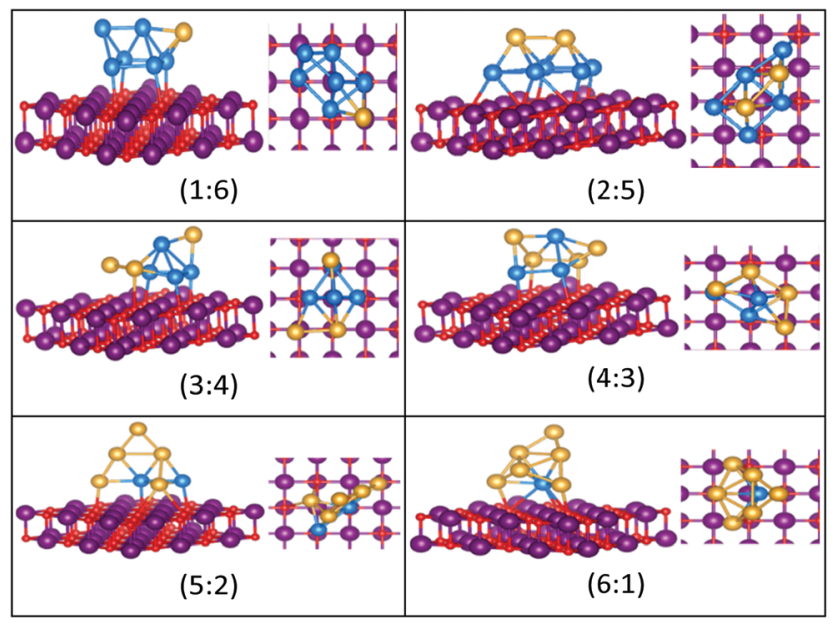

Fig. 13 Putative global minimum structures for compositions of $\mathrm{MgO}(100)$ supported AuPd nanoalloys with size $N=7$. $\mathrm{Au}, \mathrm{Pd}, \mathrm{Mg}$ and $\mathrm{O}$ are shown in gold, blue, purple, and red, respectively.

is planar. For $\mathrm{Au}_{1} \mathrm{Pd}_{4}$, the supported structure is similar to that of supported $\mathrm{Pd}_{5}$ (discussed above), having a squarebased pyramid structure. For $\mathrm{Au}_{2} \mathrm{Pd}_{3}$, the supported cluster is a distorted homotop of the gas phase structure, which allows 


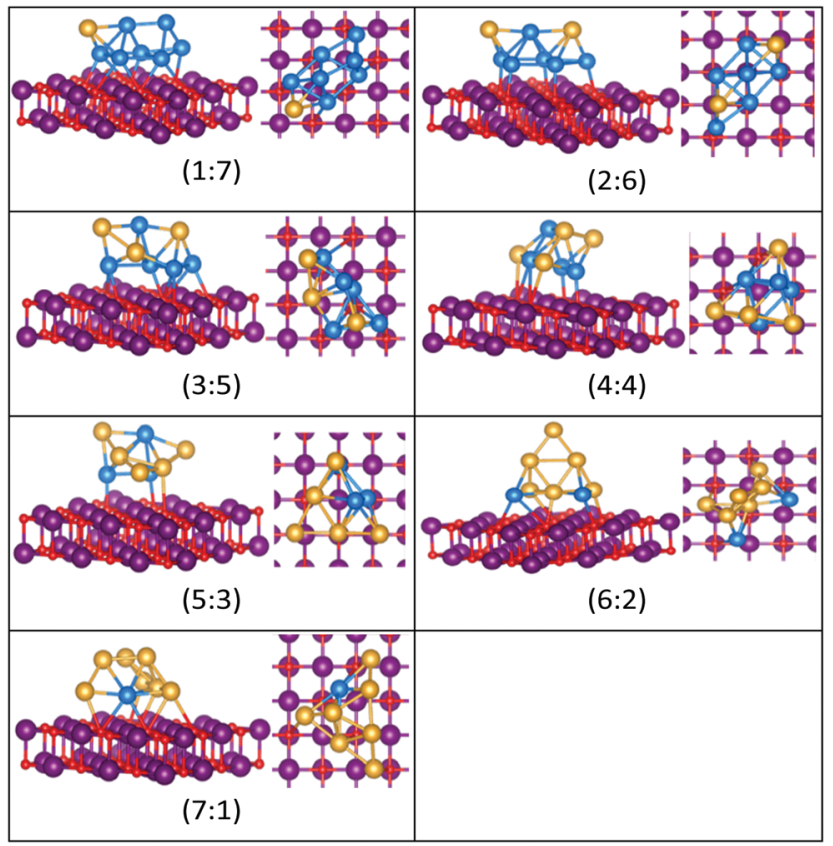

Fig. 14 Putative global minimum structures for compositions of $\mathrm{MgO}(100)$ supported AuPd nanoalloys with size $N=8$. Au, Pd, $\mathrm{Mg}$ and $\mathrm{O}$ are shown in gold, blue, purple, and red, respectively.

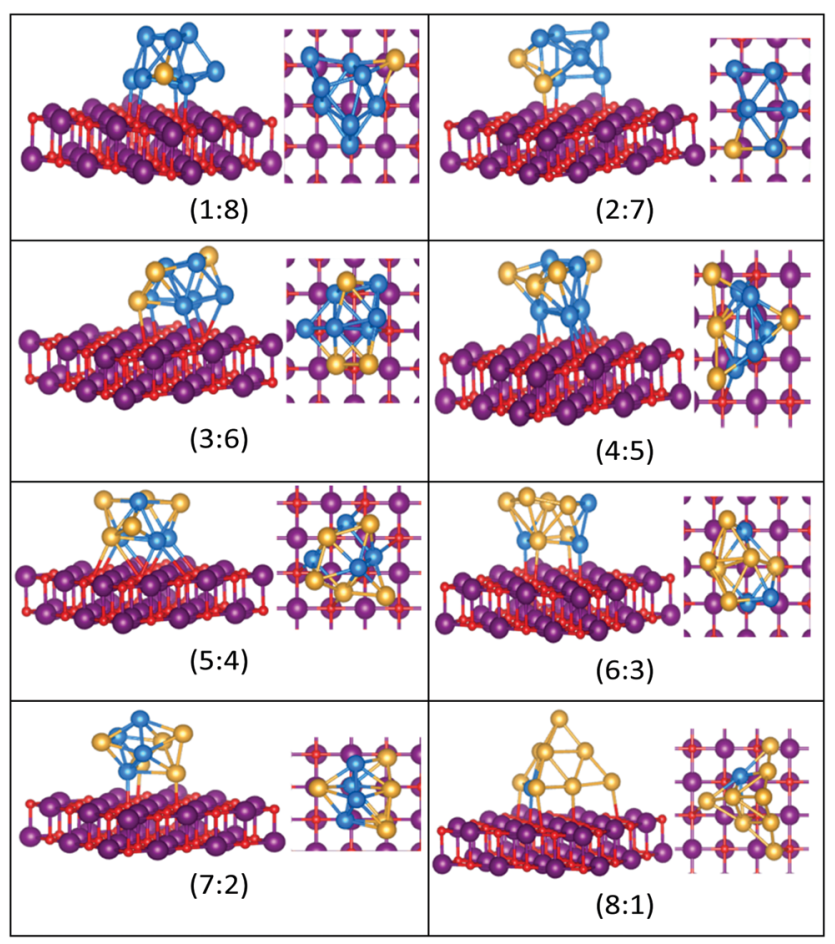

Fig. 15 Putative global minimum structures for compositions of $\mathrm{MgO}(100)$ supported AuPd nanoalloys with size $\mathrm{N}=9$. $\mathrm{Au}, \mathrm{Pd}, \mathrm{Mg}$ and $\mathrm{O}$ are shown in gold, blue, purple, and red, respectively.

all $3 \mathrm{Pd}$ atoms to bind to the surface. A structural transition occurs for the gas-phase $\mathrm{Au}_{3} \mathrm{Pd}_{2}$ cluster from $3 \mathrm{D}$ to $2 \mathrm{D}$ when supported on the surface, having a similar structure to the supported $\mathrm{Au}_{4} \mathrm{Pd}_{1}$ structure.

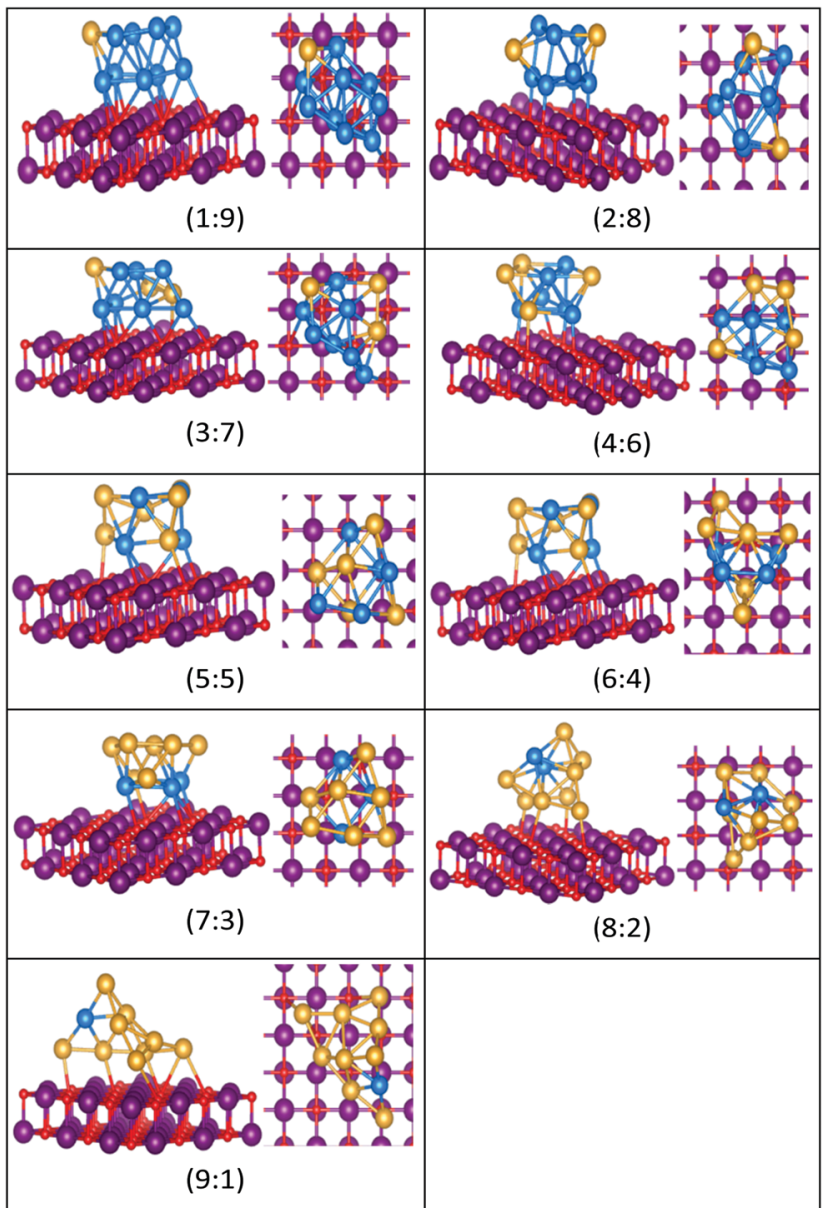

Fig. 16 Putative global minimum structures for compositions of $\mathrm{MgO}(100)$ supported AuPd nanoalloys with size $N=10$. $\mathrm{Au}, \mathrm{Pd}, \mathrm{Mg}$ and $\mathrm{O}$ are shown in gold, blue, purple, and red, respectively.

The gas-phase $\mathrm{Au}_{1} \mathrm{Pd}_{5}$ structure is an octahedron and $\mathrm{Au}_{2} \mathrm{Pd}_{4}$ and $\mathrm{Au}_{3} \mathrm{Pd}_{3}$ are both tetrahedra whereas $\mathrm{Au}_{4} \mathrm{Pd}_{2}$ and $\mathrm{Au}_{5} \mathrm{Pd}_{1}$ are an edge-bridged-capped trigonal bipyramid and planar triangle, respectively. Structural changes occur for all of these global minima on the surface except for $\mathrm{Au}_{5} \mathrm{Pd}_{1}$. The interactions between $\mathrm{Au}$ and $\mathrm{Pd}$ atoms and the $\mathrm{MgO}(100)$ surface favours face-capped square-based pyramid and facecapped trigonal bipyramid structures for supported $\mathrm{Au}_{1} \mathrm{Pd}_{5}$ and $\mathrm{Au}_{2} \mathrm{Pd}_{4}$ clusters, respectively. The supported configurations of $\mathrm{Au}_{3} \mathrm{Pd}_{3}, \mathrm{Au}_{4} \mathrm{Pd}_{2}$ and $\mathrm{Au}_{5} \mathrm{Pd}_{1}$ are all $2 \mathrm{D}$ structures. For $\mathrm{Au}_{3} \mathrm{Pd}_{3}$ on the surface, the three Pd atoms form a linear chain bonding to $\mathrm{O}$ atoms of the surface, resulting in a planar parallelogram. DFT local minimisation using the VASP code was used to confirm the parallelogram configuration by assessing an alternative planar triangular structure (as previously found for $\mathrm{Au}_{3} \mathrm{Ir}_{3}{ }^{43}$ ) for this composition (see Fig. 12). The minimisation showed that the putative GM parallelogram is indeed lower in energy than the triangle for this composition. However, both $\mathrm{Au}_{4} \mathrm{Pd}_{2}$ and $\mathrm{Au}_{5} \mathrm{Pd}_{1}$ are found to adopt the planar triangular structure on the surface with clear preference for Pd bonding to $\mathrm{O}$ atoms on the surface.

A capped octahedron is the global minimum for both $\mathrm{Au}_{1} \mathrm{Pd}_{6}$ and $\mathrm{Au}_{2} \mathrm{Pd}_{5}$, which distort on the surface to form a 
bicapped square pyramid and a square pyramid fused with a trigonal bipyramid, respectively, bound to the surface by $\mathrm{Pd}-\mathrm{O}$ bonds. In the gas phase, the $\mathrm{GM}$ for $\mathrm{Au}_{3} \mathrm{Pd}_{4}, \mathrm{Au}_{4} \mathrm{Pd}_{3}$ and $\mathrm{Au}_{5} \mathrm{Pd}_{2}$ all have edge-bridged bicapped tetrahedral structures, with the $\mathrm{Pd}$ atoms occupying the central tetrahedral core. On $\mathrm{MgO}$, they all form low-symmetry fused structures. $\mathrm{Au}_{6} \mathrm{Pd}_{1}$ has a Pd-centred planar hexagonal structure in the gas phase, while on the surface a complex 3D structure is preferred.

Both $\mathrm{Au}_{1} \mathrm{Pd}_{7}$ and $\mathrm{Au}_{2} \mathrm{Pd}_{6}$ have the same bicapped octahedral structure (with the caps adopting a "para" position) in the gasphase and both adopt structures similar to $\mathrm{Au}_{2} \mathrm{Pd}_{5}$, but with an additional atom capping the square pyramid. The gas-phase $\mathrm{Au}_{3} \mathrm{Pd}_{5}$ and $\mathrm{Au}_{4} \mathrm{Pd}_{4}$ clusters both have a "meta-" bicapped octahedral structure, but on the $\mathrm{MgO}$ surface $\mathrm{Au}_{3} \mathrm{Pd}_{5}$ adopts a polytetrahedral geometry, while $\mathrm{Au}_{4} \mathrm{Pd}_{4}$ keeps the bicapped octahedral structure, but adopts a different homotop so that 3 of the Pd atoms are in contact with the surface. The edgebridged pentagonal bipyramid structure of $\mathrm{Au}_{5} \mathrm{Pd}_{3}$ distorts to a polytetrahedral structure on the surface. The gas-phase $\mathrm{Au}_{6} \mathrm{Pd}_{2}$ cluster is a hexagonal bipyramid and its global minimum on the surface is similar to that of the supported $\mathrm{Au}_{5} \mathrm{Pd}_{2}$ structure with an additional face cap. Homotop swap and structural changes occur for the edge-bridged planar hexagon structure, the global minimum of gas-phase $\mathrm{Au}_{7} \mathrm{Pd}_{1}$, giving a 3-dimensional bent triangle bonded by the single $\mathrm{Pd}$ atom and $4 \mathrm{Au}$ atoms to the $\mathrm{O}$ atoms of the $\mathrm{MgO}$ slab.

The gas-phase $\mathrm{Au}_{1} \mathrm{Pd}_{8}$ global minimum is a face-sharing bioctahedral structure. $\mathrm{Au}_{2} \mathrm{Pd}_{7}-\mathrm{Au}_{5} \mathrm{Pd}_{4}$ have structures that can be described as the result of fusing an octahedron and a trigonal bipyramid, while $\mathrm{Au}_{6} \mathrm{Pd}_{3}$ and $\mathrm{Au}_{7} \mathrm{Pd}_{2}$ (bicapped pentagonal bipyramid) have structures which are fragments of the centred icosahedron. $\mathrm{Au}_{8} \mathrm{Pd}_{1}$ has a planar, bi-edge-bridged centred hexagon. On the $\mathrm{MgO}$ surface, complex fused structures are found, mostly consisting of 2-close packed layers of metal atoms, with $\mathrm{Pd}$ enrichment closest to the $\mathrm{MgO}$ surface.

Doping up to three $\mathrm{Au}$ atoms changes the structure of gas-phase $\mathrm{Pd}_{10}$ (discussed earlier) from an icosahedral fragment to two face-sharing octahedra, with a capping atom at the joint. The tetrahedral tetracapped octahedron is the $\mathrm{GM}$ for $\mathrm{Au}_{4} \mathrm{Pd}_{6}-\mathrm{Au}_{8} \mathrm{Pd}_{2}$, while $\mathrm{Au}_{9} \mathrm{Pd}_{1}$ has a planar, bihexagonal structure. On the $\mathrm{MgO}(100)$-support, bilayer close packed structures predominate, again with the MgO-cluster interface enriched in $\mathrm{Pd}$ to maximise $\mathrm{Pd}-\mathrm{O}$ bonding.

\subsection{Energetic analysis}

To evaluate the stability of free and supported clusters and predict the structural preferences for magic sizes, we have to calculate the excess energy $\Delta$, the second difference in energy $\Delta_{2} E$, the binding energy $E_{\mathrm{b}}$, and the adsorption energy $E_{\mathrm{ads}}$, which are defined in eqn (1)-(4). Tables S4 and S5 list the values of these energies for free and surface supported clusters (see the ESI $\dagger$ ).

Looking at the elemental properties of $\mathrm{Au}$ and Pd (shown in Table 1$),{ }^{52}$ such as surface energy $\left(E_{\text {sur }}\right)$, cohesive energy $\left(E_{\text {coh }}\right)$, atomic radius $\left(r_{\mathrm{a}}\right)$, and electronegativity $(\chi)$, we can simply predict the type of segregation in AuPd nanoalloys.
Table 1 Some elemental properties of $\mathrm{Au}$ and $\mathrm{Pd}^{52}$

\begin{tabular}{llccc}
\hline & $E_{\text {coh }} / \mathrm{eV} \mathrm{atm}^{-1}$ & $E_{\text {sur }} / \mathrm{meV} \mathrm{\AA}^{-2}$ & $r_{\mathrm{a}} / \AA$ & $\chi$ \\
\hline $\mathrm{Au}$ & 3.81 & 96.8 & 1.44 & 2.4 \\
$\mathrm{Pd}$ & 3.89 & 131 & 1.38 & 2.2
\end{tabular}

The larger values of cohesive energy and surface energy of Pd compared with $\mathrm{Au}$ explain the tendency of Pd atoms to occupy the centres and cores of clusters and the preference of Au atoms for surface positions. The atomic radius of $\mathrm{Pd}$ is smaller than for $\mathrm{Au}$. This also favours the aggregation of $\mathrm{Pd}$ atoms in the cores of clusters, whereas electron transfer between Pd and Au atoms supports the mixing of $\mathrm{Au}$ and $\mathrm{Pd}$, but this is a weak effect as the electronegativities of $\mathrm{Au}$ and $\mathrm{Pd}$ are quite similar.

The effect of mixing in a cluster system can be studied by calculating the excess energy, $\Delta$. Excess energy plots for free AuPd clusters $(m+n)=4-10$ are shown in Fig. 17 and 18 . Favourable mixing is represented by negative values of excess energies $\Delta$, whereas positive values indicate a demixing tendency.

For $(m+n=4)$ clusters, $\mathrm{Au}_{1} \mathrm{Pd}_{3}$ shows a strong demixing tendency, whereas $\mathrm{Au}_{3} \mathrm{Pd}_{1}$ exhibits the best mixing among clusters of this size. All $(m+n=5)$ clusters favour mixing and the strongest mixing is for $\mathrm{Au}_{2} \mathrm{Pd}_{3}$. However, all mixed $(m+n=6)$ clusters are energetically unfavourable relative to pure Pd and Au clusters. For $(m+n=7)$ clusters, all clusters show favourable mixing, with the largest tendency for $\mathrm{Au}_{6} \mathrm{Pd}_{1}$. For $(m+n=8)$ clusters, only $\mathrm{Au}_{1} \mathrm{Pd}_{7}$ shows unfavourable mixing and the most favourable mixing is for $\mathrm{Au}_{3} \mathrm{Pd}_{5}$. The clusters of ( $m+n=9$ and 10) favour mixing, with the most favourable mixing being for $\mathrm{Au}_{8} \mathrm{Pd}_{1}$ and $\mathrm{Au}_{6} \mathrm{Pd}_{4}$.

The mixing energy values for clusters with the same size show that variations in composition play a more important role than geometric effects in determining cluster stabilities.

The relative stabilities of clusters can be studied by calculating the second difference in energy $\Delta_{2} E$, which indicates the stability of an $\mathrm{N}$-atom cluster with respect to neighbouring sizes. Fig. 19 shows a plot of the second difference in energy $\Delta_{2} E$ for free and supported $\mathrm{Au}$ and Pd clusters. The most relatively stable clusters are indicated by significant positive peaks in $\Delta_{2} E$.

The results show that free $\mathrm{Au}_{6}$ (2D) and $\mathrm{Pd}_{6}$ (3D) clusters have a high relative stability compared to their neighbours. Accordingly, $N=6$ represents a magic size for both $2 \mathrm{D}$ Au and
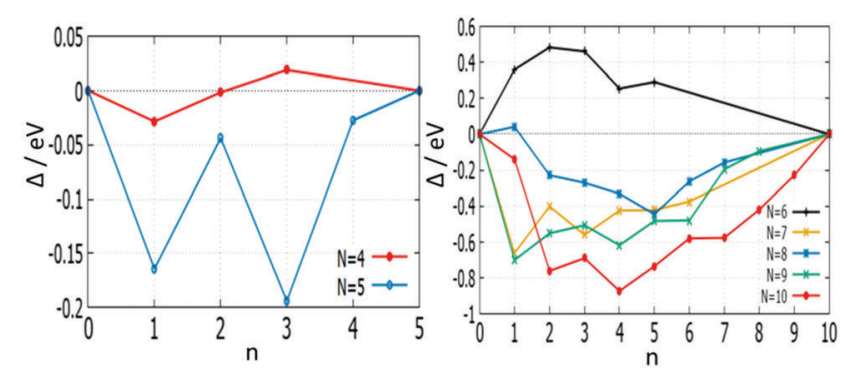

Fig. 17 Plot of mixing energy $\Delta$ against the number of Pd atoms $(n)$ for free AuPd clusters, with $N=4-10$. 


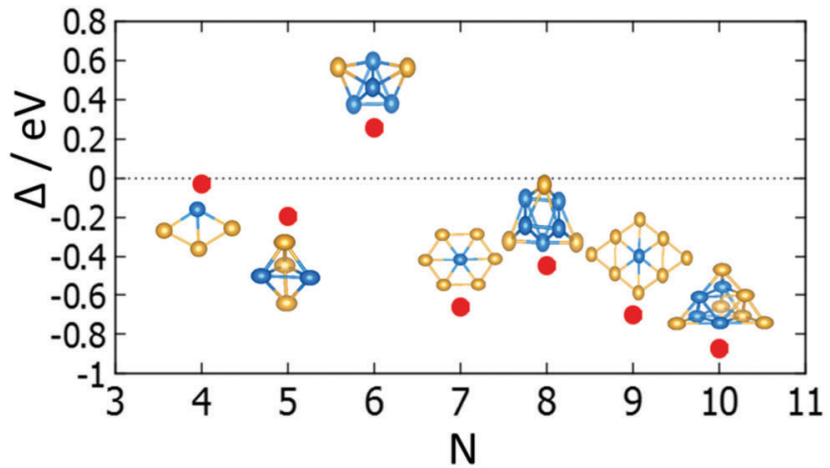

Fig. 18 For each size $(N)$, the isomer with lowest $\Delta$ is shown for free clusters.

3D Pd structures. The magic size $N=6$ for both free Au and Pd clusters explains the positive values of mixing energy of nanoalloys compared to monometallic clusters at this size. On the $\mathrm{MgO}$ surface, $\mathrm{Au}_{6}$ is still found to have the highest relative stability due to it retaining the same triangular structure both when free and supported on MgO. However, Pd clusters show a noticeable (stable) positive peak in $\Delta_{2} E$ for the supported cluster with $N=5$, rather than 6 . This is because the structure of $\mathrm{Pd}_{6}$ changes from an octahedron to a bicapped tetrahedron on the $\mathrm{MgO}$ surface, in addition to the cluster-substrate interaction effects mentioned in Section 3.1.2.

The relative stabilities of nanoclusters can be obtained by calculating the binding energy per atom, $E_{\mathrm{b}}$. A plot of the binding energies for studied clusters is shown in Fig. 20. The binding energy increases with increasing cluster size, as previously reported. ${ }^{35}$ The plot also illustrates the relative stability of nanoalloys compared to the same size of free $\mathrm{Au}$ and Pd clusters, with one exception for $N=6$, which reinforces the "magic size" hypothesis mentioned above.

There are differences between the energies of the $\mathrm{Mg}(100)$ supported global minima and the energies of the supported clusters with the slab removed. Tables S4 and S5 (see the ESI $\dagger$ ) list the adsorption energies $E_{\text {ads }}$ of the supported clusters and Fig. 21 shows a graphical representation. The plots reveal that the Pd and Pd-rich clusters tend to have the most negative $E_{\text {ads }}$ as there are a greater number of strong $\mathrm{Pd}-\mathrm{O}$ interactions. Comparing the $E_{\text {ads }}$ values for the clusters as a function of size is more complicated, however, due to the interplay between
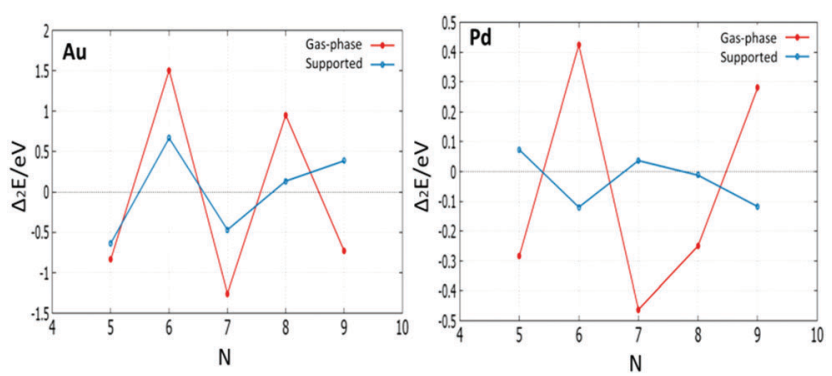

Fig. 19 The plot of the second difference in energy $\Delta_{2} E$ for free and supported Au and Pd clusters.

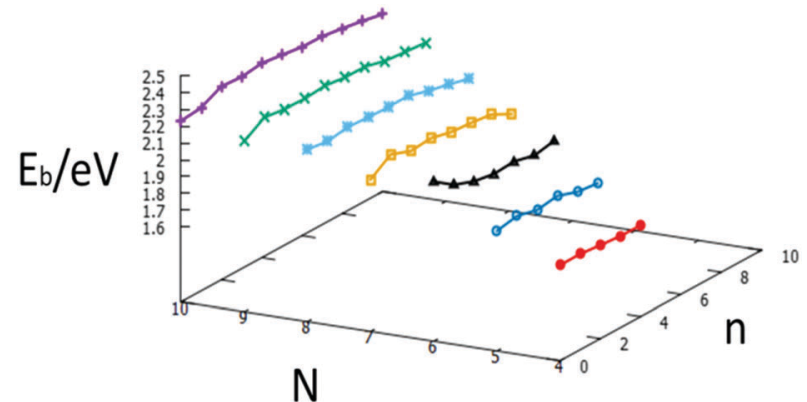

Fig. 20 Binding energies for each size $N=4-10$ against the number of $\mathrm{Pd}$ atoms, $n$, for free $\mathrm{Au}_{N-n} \mathrm{Pd}_{n}$ clusters.
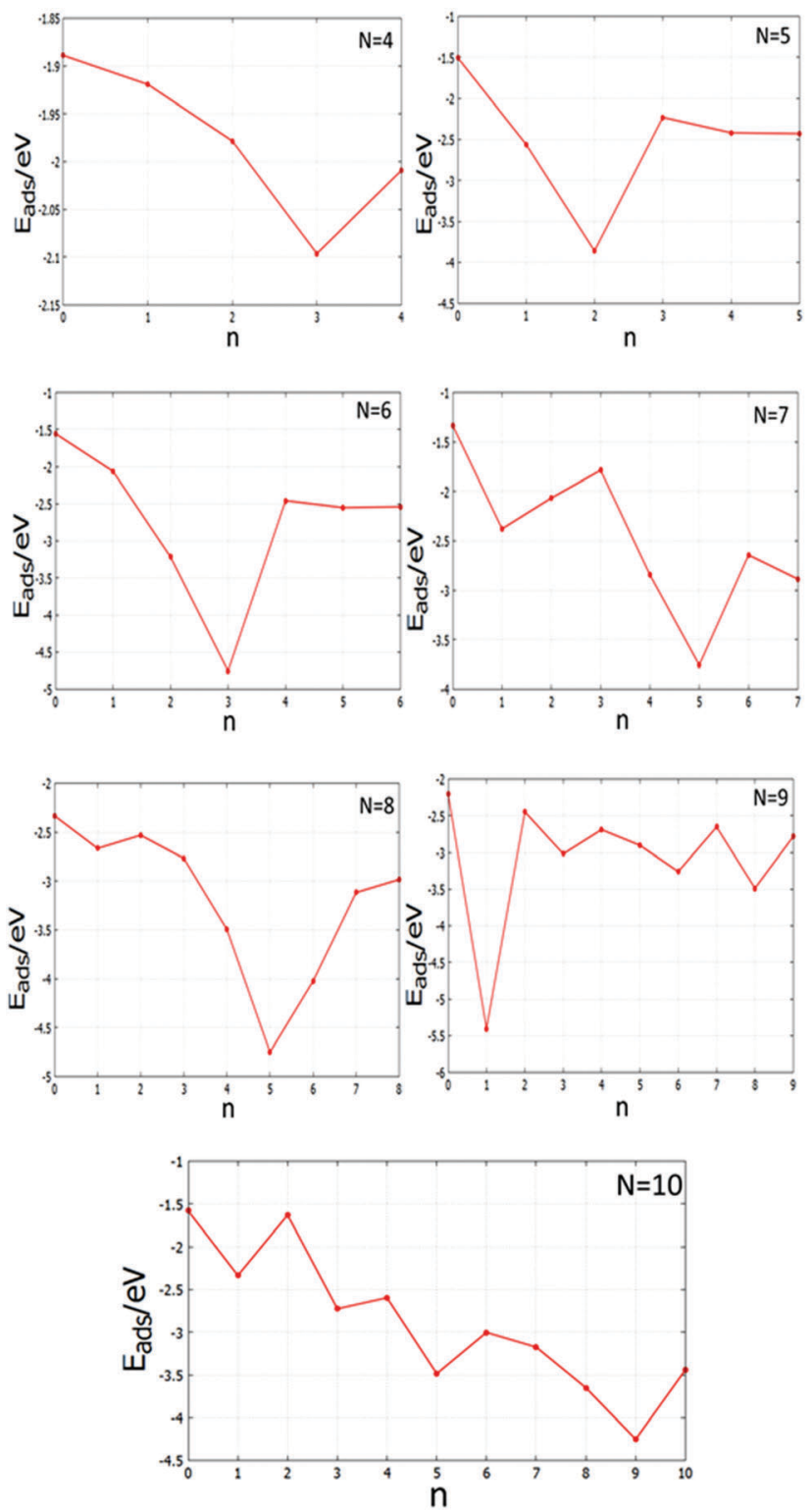

Fig. 21 Adsorption energies $E_{\text {ads }}$ against the number of Pd atoms, $n$, for the $\mathrm{MgO}(100)$-supported $\mathrm{N}=4-10$ clusters. 
structural changes and the number of interfacial Pd atoms; as for smaller clusters a higher proportion of atoms are in contact with the oxide substrate. The higher adsorption energies of Pd-doped $\mathrm{Au}$ clusters can contribute to improve catalyst performance by decreasing cluster diffusion rates and, hence, suppressing sintering.

\subsection{Systematic homotop search}

The global minima (GM) of AuPd nanoalloys have many symmetry inequivalent homotops which may have been missed by the BPGA-DFT search. Based on the GM of monosubstituted clusters and some supported-clusters, the structural energy for each symmetry inequivalent homotop was studied by DFT local minimisation using the VASP code. Tables S6-S9 (see the ESI $\dagger$ ) show energies and structures of homotops for free monosubstituted clusters and some $\mathrm{MgO}(100)$-supported clusters. Fig. 22 and 23 show plots of the relative energy $\Delta E$ against symmetry inequivalent homotop structures for these clusters.

The BPGA-DFT search for all free monosubstituted clusters $N=4-10$, successfully found the lowest energy homotop as the global minimum. For $N=4, \mathrm{Au}_{1} \mathrm{Pd}_{3}$ does not have any symmetry inequivalent homotops whereas $\mathrm{Au}_{3} \mathrm{Pd}_{1}$ has one symmetry inequivalent homotop with a relative energy of $0.50 \mathrm{eV}$.

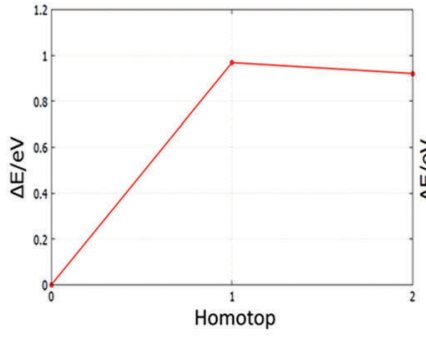

(a) $\mathrm{Au}_{4} \mathrm{Pd}_{1}$

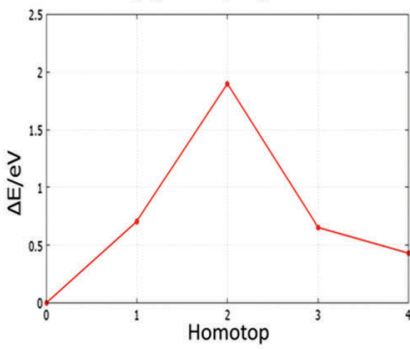

(c) $\mathrm{Au}_{7} \mathrm{Pd}_{1}$

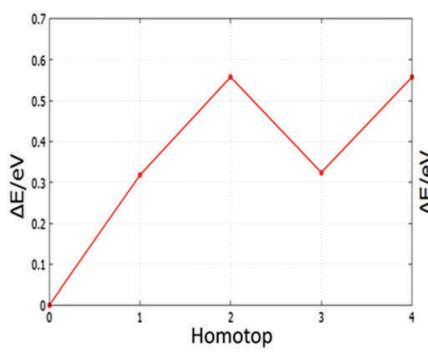

(e) $\mathrm{Au}_{1} \mathrm{Pd}_{9}$

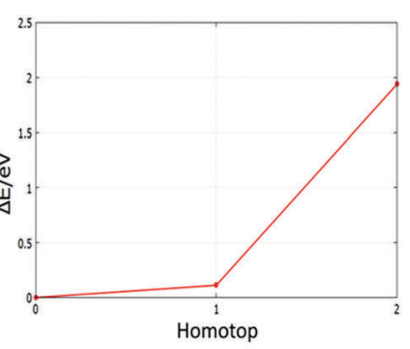

(b) $\mathrm{Au}_{1} \mathrm{Pd}_{6}$

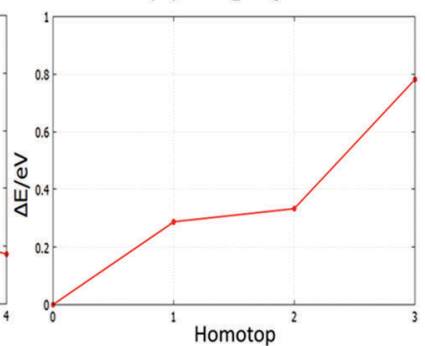

(d) $\mathrm{Au}_{8} \mathrm{Pd}_{1}$

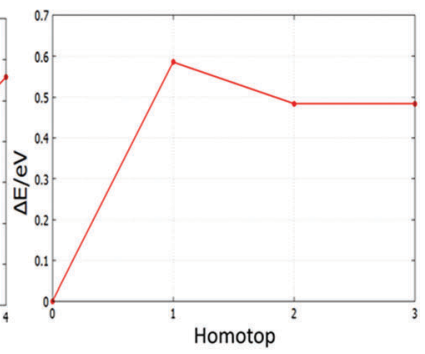

(f) $\mathrm{Au}_{9} \mathrm{Pd}_{1}$
Fig. 22 Relative energies for symmetry inequivalent homotop structures of several $\mathrm{Au}$ - and Pd-doped clusters.

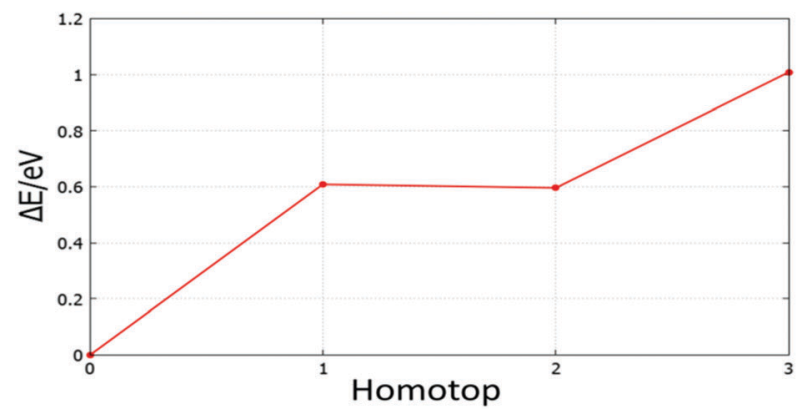

Fig. 23 Relative energy for symmetry inequivalent homotop structures of the supported $\mathrm{Au}_{5} \mathrm{Pd}_{1}$ cluster.

For $N=5$, the only symmetry inequivalent homotop for $\mathrm{Au}_{1} \mathrm{Pd}_{4}$ is $1.04 \mathrm{eV}$ higher in energy than the GM found by BPGA-DFT. $\mathrm{Au}_{4} \mathrm{Pd}_{1}$ has two symmetry inequivalent homotops and both are higher in energy than the GM, by 0.92 and $0.96 \mathrm{eV}$, as shown in Fig. 22(a).

For $N=6, \mathrm{Au}_{1} \mathrm{Pd}_{5}$ does not have any symmetry inequivalent homotops whereas $\mathrm{Au}_{5} \mathrm{Pd}_{1}$ has just one symmetry inequivalent homotop which is $2.86 \mathrm{eV}$ less stable than the GM. For $N=7$, $\mathrm{Au}_{1} \mathrm{Pd}_{6}$ has two symmetry inequivalent homotops with relative energies of $0.11 \mathrm{eV}$ and $1.93 \mathrm{eV}$, as shown in Fig. 22(b), whereas $\mathrm{Au}_{6} \mathrm{Pd}_{1}$ has one symmetry inequivalent homotop with a relative energy of $0.28 \mathrm{eV}$. For $N=8, \mathrm{Au}_{1} \mathrm{Pd}_{7}$ has just one symmetry inequivalent homotop with a relative energy of $0.35 \mathrm{eV}$, whereas $\mathrm{Au}_{7} \mathrm{Pd}_{1}$ has four symmetry inequivalent homotops which can clearly be seen in Fig. 22(c). For $N=9, \mathrm{Au}_{1} \mathrm{Pd}_{8}$ also has one symmetry inequivalent homotop with a relative energy of $0.15 \mathrm{eV}$, whereas $\mathrm{Au}_{8} \mathrm{Pd}_{1}$ has three symmetry inequivalent homotops which can be seen in Fig. 22(d). Finally, Fig. 22(e) and (f) shows the relative energies for symmetry inequivalent homotops of $\mathrm{Au}_{1} \mathrm{Pd}_{9}$ and $\mathrm{Au}_{9} \mathrm{Pd}_{1}$.

The BPGA-DFT search for $\mathrm{MgO}(100)$-supported clusters generally successfully finds the energy homotop as the global minimum. Fig. 23, for example, shows the relative energy for symmetry inequivalent homotop structures of the supported $\mathrm{Au}_{5} \mathrm{Pd}_{1}$ cluster.

\section{Conclusions}

The use of the BPGA-DFT approach has successfully allowed the global optimization of free and $\mathrm{MgO}(100)$-supported $N=4-10$ $\mathrm{Au}, \mathrm{Pd}$, and AuPd clusters. Significant structural differences between the gas-phase and surface-supported are revealed by global optimization in the presence of a $\mathrm{MgO}$ slab in addition to the clear homotop swap behaviour in mixed AuPd clusters, in order to increase the number of stabilising $\mathrm{Pd}-\mathrm{O}$ bonds. For singly doped clusters, the GM structures were confirmed by homotop reminimisation.

The BPGA-DFT calculations show that the Pd and Pd-rich clusters prefer 3D structures, while structural transitions occur for $\mathrm{Au}$ configurations from $2 \mathrm{D}$ to $3 \mathrm{D}$ upon adding more than one Pd atom. The planar structures of free Au global minima are all found to remain planar on the $\mathrm{MgO}(100)$ surface, with 
some deviation from the planarity for supported $\mathrm{Au}_{9}$ and $\mathrm{Au}_{10}$. They are also found to lie roughly perpendicular to the $\mathrm{MgO}$ surface, due to the "metal-on-top" effect. Global minima for the gas phase Pd clusters are all found to be different from their supported structures with the exception of $\mathrm{Pd}_{4}$, which retains its tetrahedral structure.

Mixing energies show the strong tendency of free $\mathrm{Au}-\mathrm{Pd}$ clusters to alloy, with the exception of $N=6$, which confirms the magic size hypothesis of pure Pd and Au clusters at this size (confirmed by findings of the binding energy $E_{\mathrm{b}}$ for nanoalloys compared to pure clusters and the second difference in energy $\Delta_{2} E$ calculations for pure $\mathrm{Au}$ and Pd clusters).

The adsorption energy $E_{\text {ads }}$ results reveal that the $\mathrm{Pd}$ and Pd-rich clusters tend to have the most negative $E_{\text {ads }}$ values. This could improve catalytic performance by suppressing cluster sintering.

\section{Acknowledgements}

H. A. Hussein is grateful to the University of Kufa and the Ministry of Higher Education and Scientific Research (Iraq) for the award of a PhD scholarship. Calculations were performed on the University of Birmingham's Blue-BEAR high-performance computer and ARCHER facilities, the UK National Supercomputing Service (http:/www.archer.ac.uk) via membership of the UK's HPC Materials Chemistry Consortium, which is funded by EPSRC (EP/L000202), and "TOUCAN: Towards an Understanding of Catalysis on Nanoalloys" membership, which is funded by EPSRC under Critical Mass Grant EP/J010804/1. The authors acknowledge Dr Christopher Heard for helpful discussions. H. A. Hussein thanks Dr Ilker Demiroglu for his valuable advice.

\section{References}

1 G. M. Whitesides, Small, 2005, 1, 172-179.

2 H. Zhang, T. Watanabe, M. Okumura, M. Haruta and N. Toshima, Nat. Mater., 2012, 11, 49-52.

3 R. Bazzi, M. Flores-Gonzalez, C. Louis, K. Lebbou, C. Dujardin, A. Brenier, W. Zhang, O. Tillement, E. Bernstein and P. Perriat, J. Lumin., 2003, 102-103, 445-450.

4 M. A. Ferrara, P. Dardano, L. De Stefano, I. Rea, G. Coppola, I. Rendina, R. Congestri, A. Antonucci, M. De Stefano and E. De Tommasi, PLoS One, 2014, 9, e103750.

5 K. Vasundhara, S. N. Achary, S. K. Deshpande, P. D. Babu, S. S. Meena and A. K. Tyagi, J. Appl. Phys., 2013, 113, 194101. 6 Y. Li, Q. Liu and W. Shen, Dalton Trans., 2011, 40, 5811.

7 R. Pillarisetty, Nature, 2011, 479, 324-328.

8 X. Liu, M. Conte, M. Sankar, Q. He, D. M. Murphy, D. Morgan, R. L. Jenkins, D. Knight, K. Whiston, C. J. Kiely and G. J. Hutchings, Appl. Catal., A, 2015, 504, 373-380.

9 Y. Gao, W. Huang, J. Woodford, L. Wang and X. C. Zeng, J. Am. Chem. Soc., 2009, 131, 9484-9485.

10 D. W. Yuan and Z. R. Liu, Phys. Lett. A, 2011, 375, 2405-2410. 11 F. Gao, Y. Wang and D. W. Goodman, J. Phys. Chem. C, 2010, 114, 4036-4043.
12 J. K. Edwards, S. J. Freakley, A. F. Carley, C. J. Kiely and G. J. Hutchings, Acc. Chem. Res., 2014, 47, 845-854.

13 J. K. Edwards, B. Solsona, E. Ntainjua N, A. F. Carley, A. A. Herzing, C. J. Kiely and G. J. Hutchings, Science, 2009, 323, 1037-1042.

14 D. I. Enache, J. K. Edwards, P. Landon, B. Solsona-espriu, A. F. Carley, A. A. Herzing, M. Watanabe, C. J. Kiely, D. W. Knight and G. J. Hutchings, Science, 2006, 311, 362.

15 A. Shayeghi, D. Götz, J. B. A. Davis, R. Schäfer and R. L. Johnston, Phys. Chem. Chem. Phys., 2015, 17, 2104-2112.

16 C. J. Heard, S. Vajda and R. L. Johnston, J. Phys. Chem. C, 2014, 118, 3581-3589.

17 R. Ismail, R. Ferrando and R. L. Johnston, J. Phys. Chem. C, 2013, 117, 293-301.

18 I. Atanasov, G. Barcaro, F. R. Negreiros, A. Fortunelli and R. L. Johnston, J. Chem. Phys., 2013, 138, 224703.

19 L. Gan, R. Tian, X. Yang, S. Peng and Y.-J. Zhao, Phys. Chem. Chem. Phys., 2011, 13, 14466-14475.

20 F. Pittaway, L. O. Paz-borbon, R. L. Johnston, H. Arslan, R. Ferrando, C. Mottet, G. Barcaro and A. Fortunelli, J. Phys. Chem. C, 2009, 113, 9141-9152.

21 J. Davis, A. Shayeghi, S. L. Horswell and R. L. Johnston, Nanoscale, 2015, 7, 14032-14038.

22 G. Kresse and J. Hafner, Phys. Rev. B: Condens. Matter Mater. Phys., 1993, 47, 558-561.

23 J. Perdew, K. Burke and Y. Wang, Phys. Rev. B: Condens. Matter Mater. Phys., 1996, 54, 16533-16539.

24 G. Kresse, Phys. Rev. B: Condens. Matter Mater. Phys., 1999, 59, 1758-1775.

25 M. Methfessel and A. T. Paxton, Phys. Rev. B: Condens. Matter Mater. Phys., 1989, 40, 3616-3621.

26 https://bitbucket.org/JBADavis/bpga/.

27 R. L. Johnston, Dalton Trans., 2003, 4193-4207.

28 B. Bandow and B. Hartke, J. Phys. Chem. A, 2006, 110, 5809-5822.

29 D. Deaven and K. Ho, Phys. Rev. Lett., 1995, 75, 288-291.

30 H. Grönbeck and P. Broqvist, J. Chem. Phys., 2003, 119, 3896.

31 R. Ferrando and A. Fortunelli, J. Phys.: Condens. Matter, 2009, 21, 264001.

32 G. Barcaro and A. Fortunelli, J. Chem. Theory Comput., 2005, 1, 972-985.

33 P. Frondelius, H. Häkkinen and K. Honkala, New J. Phys., 2007, 9, 339.

34 P. Frondelius, H. Häkkinen and K. Honkala, Phys. Rev. B: Condens. Matter Mater. Phys., 2007, 76, 1-4.

35 G. Zanti and D. Peeters, J. Phys. Chem. A, 2010, 114, 10345-10356.

36 H. Häkkinen, B. Yoon, U. Landman, X. Li, H.-J. Zhai and L.-S. Wang, J. Phys. Chem. A, 2003, 107, 6168-6175.

37 B. Assadollahzadeh and P. Schwerdtfeger, J. Chem. Phys., 2009, 131, 064306.

38 A. Walker, J. Chem. Phys., 2005, 122, 094310.

39 V. Bonačić-Koutecký, J. Burda, R. Mitrić, M. Ge, G. Zampella and P. Fantucci, J. Chem. Phys., 2002, 117, 3120.

40 D. Alamanova, Y. Dong, H. U. Rehman, M. Springborg and V. G. Grigoryan, Comput. Lett., 2005, 1, 1-12. 
41 S. Gilb, P. Weis, F. Furche, R. Ahlrichs and M. M. Kappes, J. Chem. Phys., 2002, 116, 4094-4100.

42 J. Wang, G. Wang and J. Zhao, Phys. Rev. B: Condens. Matter Mater. Phys., 2002, 66, 035418.

43 J. B. A. Davis, S. L. Horswell and R. L. Johnston, J. Phys. Chem. C, 2016, 120, 3759-3765.

44 G. Bravo-Pérez, I. L. Garzón and O. Novaro, Chem. Phys. Lett., 1999, 313, 655-664.

45 K. Pitzer, Acc. Chem. Res., 1979, 12, 271-276.

46 H. Häkkinen, M. Moseler and U. Landman, Phys. Rev. Lett., 2002, 89, 033401.
47 M. Moseler, H. Häkkinen, R. N. Barnett and U. Landman, Phys. Rev. Lett., 2001, 86, 2545-2548.

48 J. B. A. Davis, S. L. Horswell and R. L. Johnston, J. Phys. Chem. A, 2014, 118, 208-214.

49 J. Jellinek and E. B. Krissinel, Chem. Phys. Lett., 1996, 258, 283-292.

50 D. Palagin and J. Doye, Phys. Chem. Chem. Phys., 2015, 17, 28010-28021.

51 I. V. Yudanov and K. M. Neyman, Phys. Chem. Chem. Phys., 2010, 12, 5094-5100.

52 R. Ferrando, J. Jellinek and R. L. Johnston, Chem. Rev., 2008, 108, 845-910. 